Article

\title{
Evaluation of the Radiation-Protective Properties of Bi (Pb)-Sr-Ca-Cu-O Ceramic Prepared at Different Temperatures with Silver Inclusion
}

\author{
Essia Hannachi ${ }^{1, *(\mathbb{D}, \text { K. A. Mahmoud }}{ }^{2,3}{ }^{(\mathbb{C}}$, Aljawhara H. Almuqrin ${ }^{4}$, M. I. Sayyed ${ }^{1,5}\left(\mathbb{C}\right.$ and Yassine Slimani $^{6}(\mathbb{1})$ \\ 1 Department of Nuclear Medicine Research, Institute for Research and Medical Consultations (IRMC), \\ Imam Abdulrahman Bin Faisal University, Dammam 31441, Saudi Arabia; mohammed.alsyyed@iu.edu.jo \\ 2 Department of Nuclear Power Plants and Renewable Energy, Ural Federal University, St. Mira 19, \\ 620002 Yekaterinburg, Russia; kmakhmud@urfu.ru \\ 3 Nuclear Materials Authority, El-Maadi, Cairo P.O. Box 530, Egypt \\ 4 Department of Physics, College of Science, Princess Nourah Bint Abdulrahman University, \\ Riyadh 11671, Saudi Arabia; ahalmoqren@pnu.edu.sa \\ 5 Department of Physics, Faculty of Science, Isra University, Amman 11622, Jordan \\ 6 Department of Biophysics, Institute for Research and Medical Consultations (IRMC), Imam Abdulrahman Bin \\ Faisal University, Dammam 31441, Saudi Arabia; yaslimani@iau.edu.sa \\ * Correspondence: hannechi.essia@gmail.com
}

Citation: Hannachi, E.; Mahmoud, K.A.; Almuqrin, A.H.; Sayyed, M.I.; Slimani, Y. Evaluation of the Radiation-Protective Properties of $\mathrm{Bi}$ ( $\mathrm{Pb}$ )-Sr-Ca-Cu-O Ceramic Prepared at Different Temperatures with Silver Inclusion. Materials 2022, 15, 1034. https://doi.org/10.3390/ma15031034 Academic Editor: Rui Miguel Novais

Received: 22 December 2021

Accepted: 26 January 2022

Published: 28 January 2022

Publisher's Note: MDPI stays neutral with regard to jurisdictional claims in published maps and institutional affiliations.

Copyright: (c) 2022 by the authors. Licensee MDPI, Basel, Switzerland. This article is an open access article distributed under the terms and conditions of the Creative Commons Attribution (CC BY) license (https:// creativecommons.org/licenses/by/ $4.0 /)$.

\begin{abstract}
The influences of the sintering process and $\mathrm{AgNO}_{3}$ addition on the phase formation and radiation shielding characteristics of $\mathrm{Bi}_{1.6} \mathrm{~Pb}_{0.4} \mathrm{Sr}_{2} \mathrm{Ca}_{2} \mathrm{Cu}_{3} \mathrm{O}_{10}$ were studied. Three ceramics (code: $\mathrm{C} 0, \mathrm{C} 1$, and $\mathrm{C} 2$ ) were prepared as follows: $\mathrm{C} 0$ was obtained after calcination and only one sintering step, $\mathrm{C} 1$ was obtained after calcination and two sintering cycles, and $\mathrm{C} 2$ was prepared after the addition of $\mathrm{AgNO}_{3}$ at the beginning of the final sintering stage. $\mathrm{C} 2$ displayed the maximum volume fraction of the $\mathrm{Bi}-2223$ phase $(76.4 \mathrm{vol} \%)$, the greatest crystallite size, and high density. The linear mass attenuation coefficient $(\mu)$ has been simulated using the Monte Carlo simulation. The $\mu$ values are high at $15 \mathrm{keV}\left(257.2 \mathrm{~cm}^{-1}\right.$ for $\mathrm{C} 0,417.57 \mathrm{~cm}^{-1}$ for $\mathrm{C} 1$, and $421.16 \mathrm{~cm}^{-1}$ for $\left.\mathrm{C} 2\right)$, and these values dropped and became $72.58,117.83$ and $133.19 \mathrm{~cm}^{-1}$ at $30 \mathrm{keV}$. The $\mu$ value for the ceramics after sintering is much higher than the ceramic before sintering. In addition, the $\mu$ value for $\mathrm{C} 2$ is higher than that of $\mathrm{C} 1$, suggesting that the $\mathrm{AgNO}_{3}$ improves the radiation attenuation performance for the fabricated ceramics. It was demonstrated that the sintering and $\mathrm{AgNO}_{3}$ addition have a considerable influence on the ceramic thickness required to attenuate the radiation.
\end{abstract}

Keywords: ceramic; phase formation; silver; Monte Carlo; linear attenuation coefficient; radiation shielding efficiency factor

\section{Introduction}

At present, high-temperature superconductors (HTS) are one of the most examined progressive materials, owing to their promising standpoints in a variety of technology and science fields [1]. Numerous applications will be technologically advanced in radioactive surroundings, such as nuclear fusion reactors, spatial investigations, or particle accelerators, etc., where radiation can produce severe alteration in material characteristics. Predicting and controlling these alterations is within the scope of many specialists devoted to studying the influences of radiation on superconducting materials.

For example, HTS systems are utilized as protective materials in fusion reactors (FR) [2]. Therefore, it is very significant to examine the efficiency of neutron and gamma protecting superconducting materials for their promptly accessible radiation properties. Linear attenuation coefficient, the half-value layer, and radiation protecting efficiency are basic quantities required to study interactions. These parameters are reliant on the incident energy and the type and quality of the absorbing substances. Furthermore, photon 
accumulation factors (which depend on energy, thickness, and chemical compositions) are critical parameters that are necessitated to effectively protect the mixture or compound. In FR, extreme energy $(\sim 14 \mathrm{MeV})$ and high density of neutrons is induced during the tritium-deuterium fusion reaction. High energy neutrons cause diverse reactions with fusion reactor building materials to emit $\gamma$ rays with energies of up to 10-20 MeV [3].

Among the well-known HTS, $\mathrm{Bi}_{2} \mathrm{Sr}_{2} \mathrm{Ca}_{\mathrm{n}-1} \mathrm{Cu}_{\mathrm{n}+1} \mathrm{O}_{2 \mathrm{n}+6}$ (BSCCO for brevity; $n=1,2$, and 3), which involves bismuth, strontium, calcium, and copper oxide, is an interesting class of high-conductive systems. It is known that this system has three phases, 2201, 2212, and 2223, according to $n$ value. Of these phases, phases $2212(n=1)$ and $2223(n=2)$ are more significant owing to their critical temperatures exceeding the liquid nitrogen boiling point [4]. In addition to their high critical temperature, this system exhibits many other advantages, including high critical current, the nonexistence of dust rare earth elements, water resistance, purity, and abundance of superconducting elements. Many researchers have devoted study to the effects of sintering temperature, sintering duration, doping, and pressure on the formation of highly stable BSCCO materials [5-8]. Various kinds of chemical and physical characteristics of this type of HTS have been investigated [9-11]. Yet, their radiation shielding efficiency is very scarce in the literature, unlike the shielding properties of concretes [12,13], glass, and alloys [14-17]. In a recent study, Singh et al. [18] studied the radiation shielding performances of some superconducting ceramics, including non-centrosymmetric (NCS), iron-based, and oxide-based superconductors. It was found that an iron-based superconductor is efficient as a fast-neutron shielding material for neutron energies ranging from 2 to $12 \mathrm{MeV}$, while NCS and oxide-based superconductors are superior gamma-rays shielding materials.

In the current work, we aim to study the structure development and the radiation shielding traits of $\left(\mathrm{Bi}_{1.6}, \mathrm{~Pb}_{0.4}\right) \mathrm{Sr}_{2} \mathrm{Ca}_{2} \mathrm{Cu}_{3} \mathrm{O}_{10}$ ceramic prepared under different sintering cycles and with $\mathrm{AgNO}_{3}$ addition during the final sintering step. $\mathrm{AgNO}_{3}$ has been widely used as the most suitable dopant to improve the physical properties of almost all superconducting materials. The positive effects of silver addition on the physical properties of ceramic superconductors are to promote crystallization, mechanical toughness, and oxygen diffusion [19,20]. For instance, Abdeen et al. [21] showed that the addition of nano-silver to the superconducting phase improved the volume fraction, superconducting, and mechanical properties of the material. In addition, the addition of silver results in the growth of grains leading to the reduction in grain boundaries and porosity and the improvement of intergranular links [22,23]. For example, D. Sýkorová et al. studied the effect of the addition of different amounts of silver $(5,10$, and $15 \mathrm{wt}$.\%) on the performance of Bi-based superconductors, and they demonstrated that $15 \mathrm{wt} \%$ of silver addition is the optimal amount for the formation of a low porous and high dense sample with good superconducting properties [24]. Thus, it is expected that superconducting ceramics with the desired radiation shielding properties will be obtained.

Based on this literature review, the phase formation and radiation shielding characteristics of the different proposed ceramics are compared and discussed. The results obtained can be advantageous in diverse applications of superconductors for radiation protecting applications.

\section{Experiment}

\subsection{Synthesis Protocol and Experimental Characterization}

A bismuth-based ceramic with a nominal composition of $\mathrm{Bi}_{1.6} \mathrm{~Pb}_{0.4} \mathrm{Sr}_{2} \mathrm{Ca}_{2} \mathrm{Cu}_{3} \mathrm{O}_{10}$ was fabricated by the solid-state route. The raw powders are consistent with $\mathrm{CaCO}_{3}(99.9 \%)$, $\mathrm{SrCO}_{3}(99.9 \%)$, and $\mathrm{CuO}(99.9 \%)$. A stoichiometric mixture of these starting powders was subjected to calcination in the air for $24 \mathrm{~h}$ at $930{ }^{\circ} \mathrm{C}$ to form an oxide precursor without any remainders of carbonates. Then, the precursor oxide was mixed with $\mathrm{PbO}$ and $\mathrm{Bi}_{2} \mathrm{O}_{3}$ powders ( $0.4 \mathrm{~Pb}$ per formula unit) and placed into a boat crucible alumina before being heat-treated in the air in a tubular furnace at $835^{\circ} \mathrm{C}$ for $140 \mathrm{~h}$, and finally fast cooled to room temperature to produce an intermediate compound, $\mathrm{Bi}_{1.6} \mathrm{~Pb}_{0.4} \mathrm{Sr}_{2} \mathrm{Ca}_{2} \mathrm{Cu}_{3} \mathrm{O}_{10}$. The 
resulting intermediate compound (IC; referred to as $\mathrm{C} 0$ ) is dark. During the second heat treatment, $15 \mathrm{wt} . \%$ of $\mathrm{AgNO}_{3}$ was added to the IC. Both powders were thoroughly mixed and ground by hand using an agate mortar with pestle to form a homogeneous mixture. The $0 \mathrm{wt} . \%$ powder was also considered, so it was hand-ground as with the powder added with $\mathrm{AgNO}_{3}$ to certify similar surrounds for all the ceramics. This $0 \mathrm{wt}$.\% powder was considered as a reference (referred to as C1) and it was compared with $\mathrm{C} 0$ (the one that has not subjected to the second heat treatment stage) and with powder prepared with silver addition (referred to as C2). Both powders were then subjected to a sintering step at $850{ }^{\circ} \mathrm{C}$ in the air for $156 \mathrm{~h}$ after being uniaxially pressed into pellets at $17 \mathrm{MPa}$. The pellets were then slowly cooled at a rate of $13{ }^{\circ} \mathrm{C} / \mathrm{min}$ to form a dense and well-compacted ceramic. Table 1 illustrates the ceramic code with their sintering conditions and their density values.

Table 1. Sintering conditions of $\mathrm{C} 0, \mathrm{C} 1$, and $\mathrm{C} 2$ ceramics.

\begin{tabular}{|c|c|c|c|c|c|}
\hline \multirow{2}{*}{$\begin{array}{l}\text { Ceramic } \\
\text { Code }\end{array}$} & \multicolumn{4}{|c|}{ Sintering Conditions } & \multirow{2}{*}{$\begin{array}{r}\text { Density } \\
\left(\mathrm{g} / \mathrm{cm}^{3}\right)\end{array}$} \\
\hline & $\begin{array}{c}\text { Calcination } \\
\left(930^{\circ} \mathrm{C}, 24 \mathrm{~h}\right)\end{array}$ & $\begin{array}{c}\text { First Sintering } \\
\text { Step }\left(835^{\circ} \mathrm{C}, 140 \mathrm{~h}\right)\end{array}$ & $\begin{array}{l}\text { Second Sintering } \\
\text { Step }\left(850^{\circ} \mathrm{C}, 156 \mathrm{~h}\right)\end{array}$ & $\begin{array}{c}\operatorname{AgNO}_{3} \\
\text { Addition }\end{array}$ & \\
\hline $\mathrm{CO}$ & $x$ & $x$ & - & - & 3.25 \\
\hline C1 & $\times$ & $x$ & $x$ & - & 6.25 \\
\hline $\mathrm{C} 2$ & $\times$ & $x$ & $x$ & $x$ & 6.85 \\
\hline
\end{tabular}

X-ray powder diffraction (XRD; Philips 1710 diffractometer) was performed using $\mathrm{CuK} \alpha$ radiations, with a scanning rate of $0.002^{\circ} / \mathrm{s}$ and a step of $0.02^{\circ}$. These scanning parameters gave precise diffraction peaks of integral areas for calculating phase concentration. Before the XRD measurement step, the sintered ceramics were finely hand-ground. This step purposes to prevent any orientation of preferred grains within the material, and therefore to safeguard an arbitrary spatial distribution of the intensity of the reflection.

\subsection{Prediction of the Radiation Shielding Characteristics Using Monte Carlo Simulation}

The shielding properties of the fabricated ceramics were evaluated via two different methods: Theoretically, by means of the XCOM program and based on the NIST database created by Berger and Habull 1983, while the second method is Monte Carlo simulation (MC). The MC method, reported in many previous articles, proves its ability to predict the shielding behavior of any material currently using the ENDF/B-VI.8 database [25]. To obtain highly accurate results for the shielding parameters, an input file was created to accurately describe the experimental measurements. A 3D draw for the input file was exemplified in our previous work [26]. The mentioned 3D draw shows that an outer shielding cylinder of lead was employed to protect the geometry from the background activity. This outer cylinder has a thickness of $5 \mathrm{~cm}$ and a highest measurement of $35 \mathrm{~cm}$. It is standing vertically along the $Z$ direction. The outer cylinder contains various components such as radioactive source, collimators, a sample, and a detector. The radioactive source was set to emit $\gamma$ photons in the interval of energy ranging between 0.015 and $15 \mathrm{MeV}$; it has a diameter of $1 \mathrm{~cm}$ and thickness of $0.3 \mathrm{~cm}$. This radioactive source is surrounded by a collimator of lead with a highest point of $7 \mathrm{~cm}$ and a diameter of $5 \mathrm{~cm}$. The collimator is used to absorb the scattered photons from the radioactive source and collimate the incident photons. The photons then act on the ceramic samples which have diameters of $2 \mathrm{~cm}$ and various thicknesses. In the distance between the ceramic sample and detector, another collimator is used to collimate the photons transmitted from the sample. The detector was assumed to be an F4 tally to record the number of photon flux per unit volume of the cell. The simulation ran out with NPS card $10^{6}$ historical. The output file recorded a relative error of $\pm 0.1 \%$. After that, all shielding parameters were calculated based on the mean track length of $\gamma$ photons predicted by MC simulation, as discussed deeply in previous publications $[26,27]$. 


\section{Results and Discussion}

\subsection{Phase Composition}

To identify the phase composition of our $\mathrm{Bi}(\mathrm{Pb})-\mathrm{Sr}-\mathrm{Ca}-\mathrm{Cu}-\mathrm{O}$ prepared ceramics and assess the development of phase transformation, X-ray measurements were taken in the $2 \theta$ range of $3-60^{\circ}$, and all the spectra are illustrated in Figure 1. Characteristic peaks matching the various phases were indicated on different peaks. In all spectra, the Bi-2223 and the Bi-2212 phases are presented by 3 and 2 abbreviations, respectively. To guess the volume fraction of each phase, the intensities of the XRD peak were considered, taking the relative intensities of the peaks in the pure compounds provided by the XRD file. The volume fraction for a given phase can be computed using the following equation:

$$
V(\text { phase } i)=\frac{\sum I \text { phasei }}{\sum I \text { phasei }+\sum I \text { other phases }} \times 100
$$

where phase $i$ is the $\mathrm{Bi}-2223$ or Bi-2212 phase. In the first part of this work, we will study the influences of sintering and $\mathrm{AgNO}_{3}$ addition on the phase formation of $\mathrm{Bi}(\mathrm{Pb})-\mathrm{Sr}-\mathrm{Ca}-\mathrm{Cu}-\mathrm{O}$ ceramic.

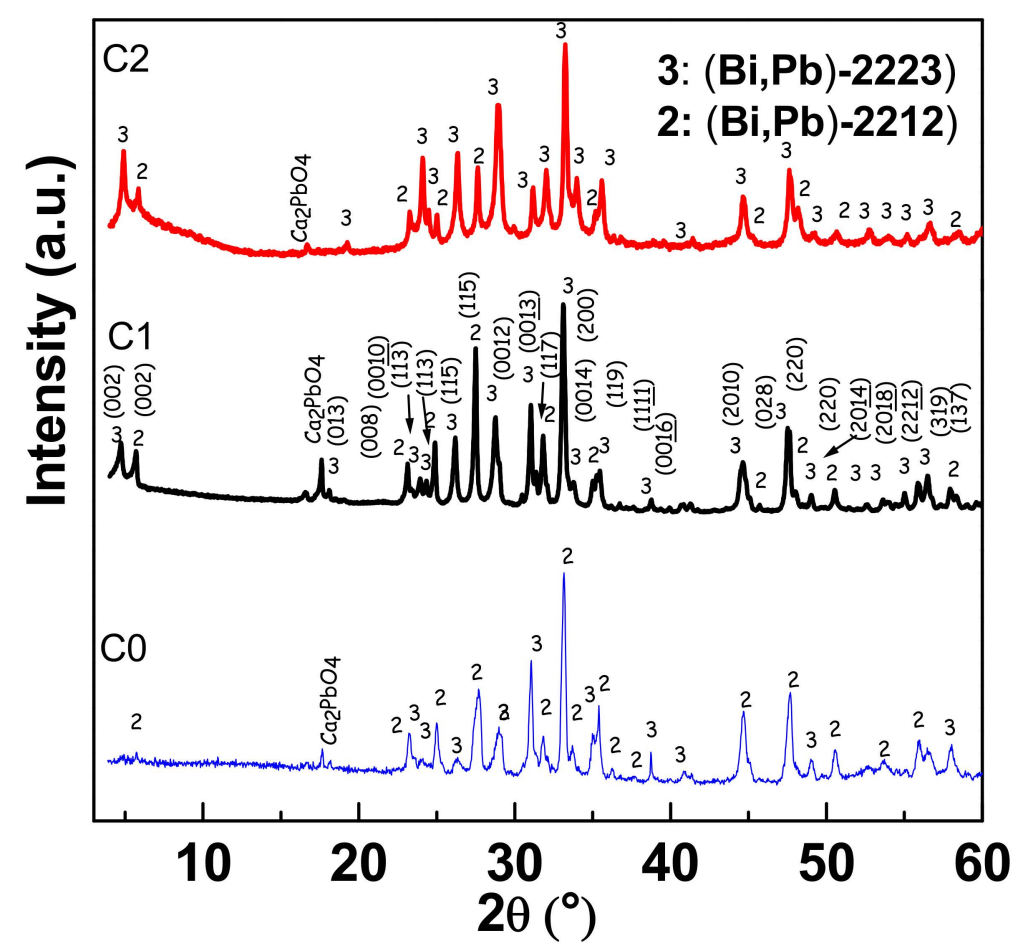

Figure 1. XRD patterns of C0 (blue spectrum), C1 (black spectrum), and C2 (red spectrum).

\subsubsection{Effect of the Second Thermal Cycle}

The blue XRD spectrum in Figure 1 corresponds to the $\mathrm{C} 0$ ceramic. This ceramic is the IC obtained after calcination and only one first step cycle. The analysis of these spectra indicates that this ceramic is predominantly composed of $(\mathrm{Bi}, \mathrm{Pb})-2212$ phase $(65.3 \mathrm{vol} \%)$, $34.7 \mathrm{vol} \%$ of $(\mathrm{Bi}, \mathrm{Pb})-2223$ phase, and a trivial amount of $\mathrm{Ca}_{2} \mathrm{PbO}_{4}$ as the second phase. In the sintered ceramic $\mathrm{C} 1$, the second sintering step at $850{ }^{\circ} \mathrm{C}$ induces an increase in volume fraction of the $(\mathrm{Bi}, \mathrm{Pb})-2223$ phase at the expense of the $\mathrm{Bi}-2212$ phase. This is clearly distinguished by the typical (002) peak related to the ( $\mathrm{Bi}, \mathrm{Pb})-2223$ phase detected at $2 \theta=4.72$ in the black spectrum of Figure 1. This characteristic peak is not observed in the blue spectrum ( $\mathrm{C} 0$ ceramic). This result seems to indicate that a large amount of the $\mathrm{Bi}-2212$ phase converted into the $(\mathrm{Bi}, \mathrm{Pb})-2223$ phase and that this transformation does not favor any new crystallographic orientation. The Bi-2212 phase is in the form of sheets obtained after the first sintering step, can function as a precursor, and changes chemically 
to convert to the $(\mathrm{Bi}, \mathrm{Pb})-2223$ phase. Furthermore, this transformation can be explained by the conversion of the Bi-2212 phase in the occurrence of a liquid phase during the second sintering at $850{ }^{\circ} \mathrm{C}$. This liquid phase is essential for the formation of the Bi-2223 phase. Yet, it should be appropriately transformed to Bi-2223 to increase the 2223 fraction [28]. Thus, the second sintering stage is favorable for converting liquid to the Bi-2223 phase.

\subsubsection{Influence of $\mathrm{AgNO}_{3}$ Addition}

The red spectrum in Figure 1 corresponds to $\mathrm{C} 2$ ceramic obtained after two heat treatment cycles with $\mathrm{AgNO}_{3}$ addition. The analysis of this spectrum showed that the $\mathrm{Bi}-2223$ is present as the main phase in this ceramic, while $\mathrm{Bi}-2212$ appears as a minor phase. The concentration of the Bi-2223 phase is remarkably increased with $\mathrm{AgNO}_{3}$ addition. The volume fractions of Bi-2223 augmented from $53.3 \mathrm{vol} \%$ for $\mathrm{C} 1$ ceramic to $76.4 \mathrm{vol} \%$ for C2 ceramic (Figure 2). Meanwhile, Bi-2212 halved from $46.7 \mathrm{vol} \%$ for C1 ceramic to $23.6 \%$ for $\mathrm{C} 2$ ceramic. This sharp reduction in the volume fraction of $\mathrm{Bi}-2212$ in the $\mathrm{C} 1$ sample indicates that the majority of this phase was converted to $(\mathrm{Bi}, \mathrm{Pb})-2223$ phase. This phase conversion was fairly speedy with $\mathrm{AgNO}_{3}$ addition, compared to the ceramic prepared without $\mathrm{AgNO}_{3}$. The addition of $\mathrm{AgnO}_{3}$ significantly improves the $(\mathrm{Bi}, \mathrm{Pb})-2223$ formation rate in ceramics. This signifies that the presence of $\mathrm{AgNO}_{3}$ led to a change in the homogeneity of the transient liquid composition, its viscosity, and the rate formation of the main phase. Hence, the addition of $\mathrm{AgNO}_{3}$ may most probably contribute to the creation of gas pockets which facilitate the liquid phase diffusion between the Bi-2212 sheets, thus promoting the proliferation of the nucleation sites and therefore the growth of the phase (Bi, Pb)-2223.

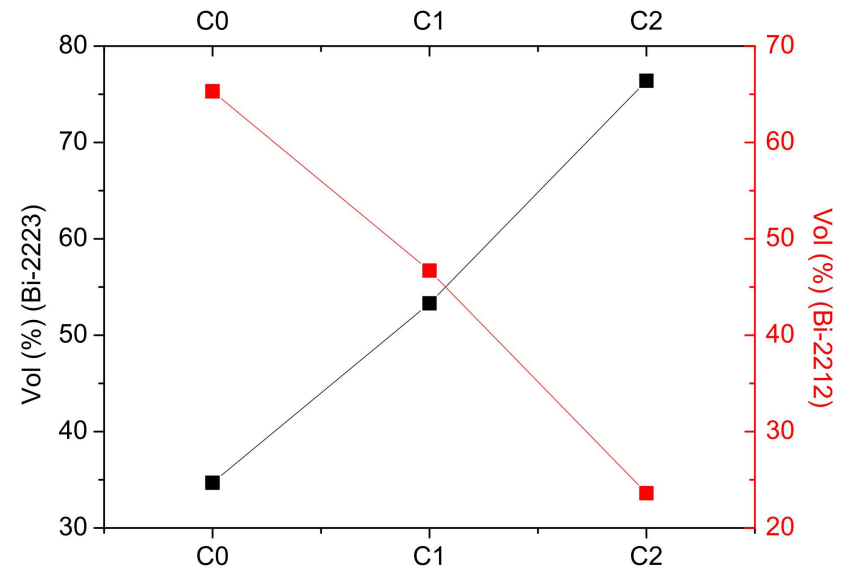

Figure 2. The volume fraction of $\mathrm{Bi}-2212$ and $\mathrm{Bi}-2223$ phases in different $\mathrm{C} 0, \mathrm{C} 1$, and $\mathrm{C} 2$ ceramics.

The crystallites size $D$ of the different $C 0, C 1$, and $C 2$ ceramics were determined using the Debby-Scherrer equation, as follows [29]:

$$
D=\frac{K \lambda}{\beta \cos \theta}
$$

where $K$ is a dimensionless constant, $\beta$ is the peaks' width at half maximum intensity, and $\lambda$ is the wavelength $(\lambda=0.15406 \mathrm{~nm})$.

Figure 3 displays the evolution of the crystal size $D$. The crystal size shows a gradual increase from $48.15 \mathrm{~nm}$ for $\mathrm{C} 0$ to 52.50 for $\mathrm{C} 1$ ceramic, indicating the beneficial effect of the second sintering process in enhancing the bonding of BSCCO. When compared to the three as-prepared ceramics, C2 ceramics exhibits the highest value of crystallite size D $(61.9 \mathrm{~nm})$. This means that the addition of $\mathrm{AgNO}_{3}$ extremely strengthens the bonding between the BSCCO grains, positively affects the bond lengths, and increases the interplane coupling. It can then be assumed that the silver resides at the grain boundaries, filling the pores 
between the grains and further aiding in the conversion of the Bi-2212 phase to the $\mathrm{Bi}-2223$ phase via the liquid phase.

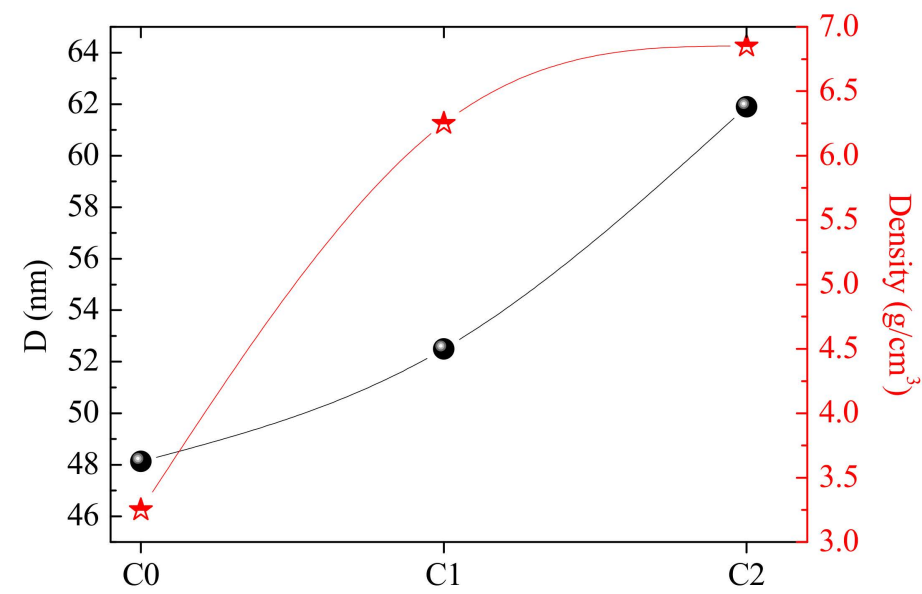

Figure 3. Crystallite size (D) and density ( $\rho)$ in C,$C 1$, and C2 ceramics. Round symbols correspond to $\mathrm{D}$ values and star symbols correspond to density values.

The density $\rho$ of the different ceramics was calculated. The different values are listed in Table 1, and their evolution is shown in Figure 3. It is clear that $\rho$ has a similar variation as the crystallite size. The density $\rho$ follows this order: $\mathrm{C} 2>\mathrm{C} 1>\mathrm{C} 0$. This implies that the sintering step increases the crystallite size and, consequently, leads to more dense ceramics. The highest value of $\rho$ is obtained for $\mathrm{C} 2$ ceramic displaying the greatest crystallite size $\mathrm{D}$. This can be due to the $\mathrm{AgNO}_{3}$, which may diffuse at grain boundaries, leading to improved interconnectivity and consequently resulting in the growth of grains and densification of the material. Our results are consistent with those reported by D. Sýkorová et al. [24]. Such a result is beneficial for the radiation shielding performances of the material. This will be deeply discussed in the next section of this work.

\subsection{Radiation Shielding Parameters}

To examine the radiation attenuation properties of the three prepared ceramics, the linear mass attenuation coefficients $(\mu)$ have been simulated by using the Monte Carlo simulation (MC). To validate the predicted $\mu$ obtained by MC, we used XCOM for the sake of comparison between the simulated and theoretically calculated $\mu$. This is a very important step because we will use the MC results to predict the other crucial radiation attenuation parameters, such as the mean free path and others. The comparison will also allow for estimating of accuracy in the transmission geometry setup for MC. In Figure 4, we presented the comparison in the predicted $\mu$ values via MC and those determined by XCOM at some energies $(0.03,0.08,0.15,0.662,1.173$, and $15 \mathrm{MeV})$.

For the three ceramics, good agreement is reported between the $\mu$ obtained in the two methods, and the difference in the $\mu$ between the MC and XCOM at each energy given in the figure is extremely small, and less than $3 \%$ in most cases. Accordingly, perfect compatibility is reported between the simulation and theoretical data. Hence, the present transmission geometry setup for MC was repeated for the same ceramics but at a wide energy range, and the results are given in Figure 5. The $\mu$ values are high at $15 \mathrm{keV}$ $\left(257.2 \mathrm{~cm}^{-1}\right.$ for $\mathrm{C} 0,417.57 \mathrm{~cm}^{-1}$ for $\mathrm{C} 1$, and $421.16 \mathrm{~cm}^{-1}$ for $\left.\mathrm{C} 2\right)$. These values sharply dropped and are $72.58,117.83$, and $133.19 \mathrm{~cm}^{-1}$ at $30 \mathrm{keV}$, while at $50 \mathrm{keV}$, they are 18.80 , 30.52 , and $34.52 \mathrm{~cm}^{-1}$ for the same respective ceramics. Thus, the $\mu$ starts with high values and quickly declines with increasing energy. This is ascribed to the photoelectric effect. This effect is important for the low energy radiation and highly depends on the energy (inverse relation), so this explains the previous trend in the $\mu$ between 15 and $50 \mathrm{keV}$. This high reduction in the $\mu$ is not observed at higher energy, and the $\mu$ is changed very slowly with the energy between 0.3 and $1.5 \mathrm{MeV}$. This is due to the Compton scattering. For C0, 
the $\mu$ values are $0.452,0.344,0.294$, and $0.244 \mathrm{~cm}^{-1}$ at $0.5,0.662,0.8$, and $1 \mathrm{MeV}$. At 10 and $15 \mathrm{MeV}$, the $\mu$ has an opposite trend with the energy, i.e., we found a slight increase in the $\mu$ which is ascribed to the pair production process [30]. On the other hand, we can understand the influence of sintering and the effect of silver on the $\mu$ values. Let us compare the $\mu$ between the first and second samples (before and after sintering). We can see that the $\mu$ for the ceramic sample after sintering is much higher than the ceramics before sintering. Due to the high temperature and pressure during the sintering process, the grain boundaries were reduced. The density of the ceramics was notably enhanced, so we found that the $\mu$ for $\mathrm{C} 1$ is higher than that of $\mathrm{C} 0$. When we compare the $\mu$ for $\mathrm{C} 1$ and $\mathrm{C} 2$, we can see that the $\mu$ for $\mathrm{C} 2$ is higher than that of $\mathrm{C} 1$. This is because $\mathrm{C} 2$ contains $\mathrm{AgNO}_{3}$. Therefore, we can conclude that the $\mathrm{AgNO}_{3}$ improves the radiation attenuation performance for the prepared ceramics.
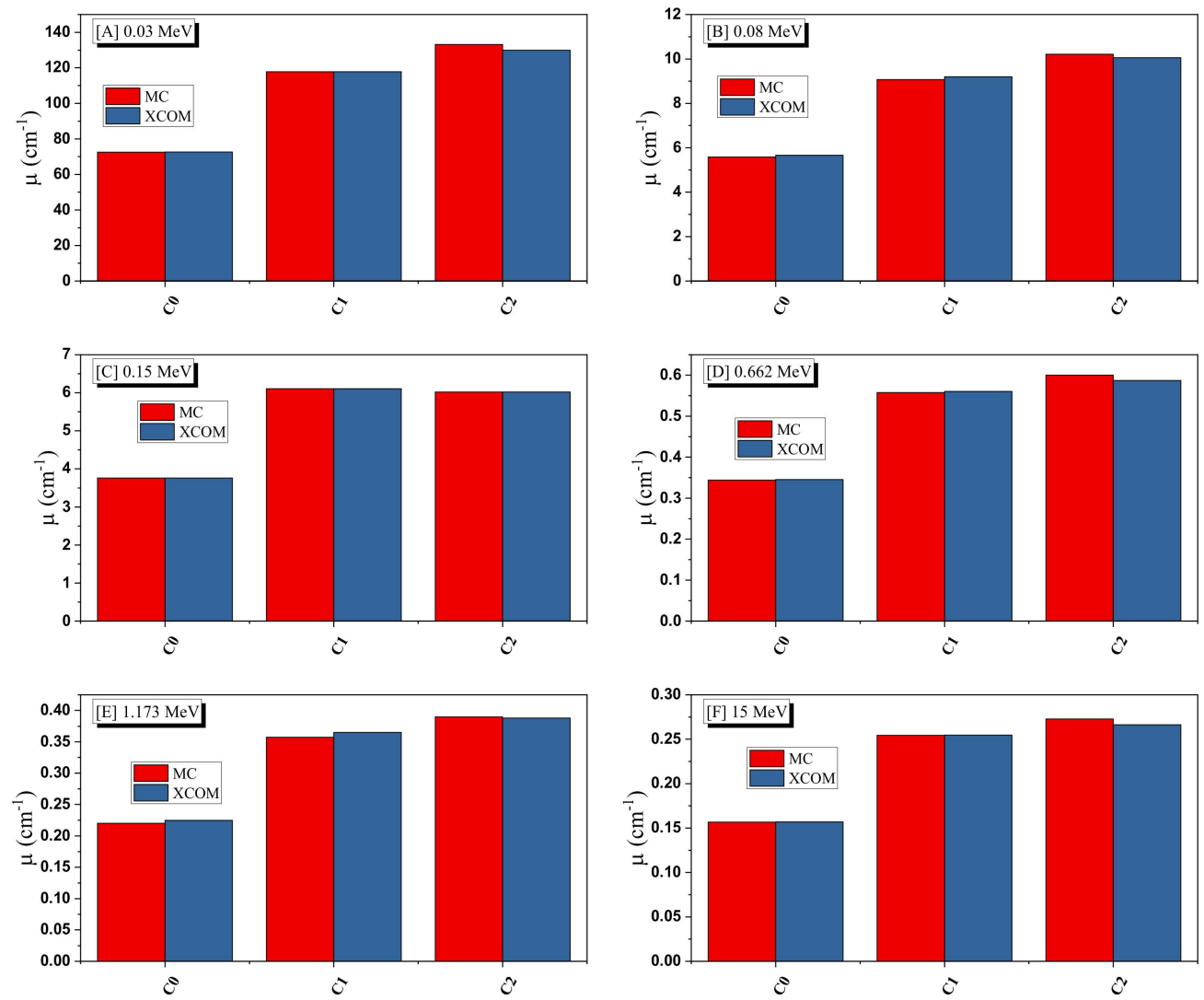

Figure 4. Comparison between the simulated and calculated linear attenuation coefficient for the fabricated ceramics at (A) $0.03 \mathrm{MeV}$, (B) $0.08 \mathrm{MeV}$, (C) $0.15 \mathrm{MeV}$, (D) $0.662 \mathrm{MeV}$, (E) $1.173 \mathrm{MeV}$ and (F) $15 \mathrm{MeV}$.

To the deep investigation of the influence of both the sintering and the effect of silver on the attenuation ability of the prepared ceramics, we plotted the half-value layer $\left(\Delta_{0.5}\right)$ for $\mathrm{C} 0$ and $\mathrm{C} 1$ at low energies (between 0.015 and $0.1 \mathrm{MeV})$, moderate energy (0.15-1.332 MeV), and high energy (1.5-15 MeV) in Figure 6A-C. In addition, in Figure 7A-C, we plotted the $\left(\Delta_{0.5}\right)$ for $C 1$ and $C 2$ at the same respective energies. Examining the data in Figure 6, we can see that, at the three selected regions, the $\Delta_{0.5}$ for $\mathrm{C} 1$ is smaller than that of $\mathrm{C} 0$. Therefore, it is reasonable to conclude that the sintering has a considerable influence on the thickness of the glass that is needed to attenuate the radiation. From Figure 6A, we see that the sintering has a weak effect on the $\Delta_{0.5}$ at $0.015 \mathrm{MeV}$, since this is very low energy, and thus, the ceramics without and with sintering can attenuate these low energy photons. Moreover, from the same subfigure, we can see that the $\Delta_{0.5}$ at $0.1 \mathrm{MeV}$ has an opposite trend; the $\Delta_{0.5}$ is increased with increasing the energy, but at this energy, we found that the $\Delta_{0.5}$ is decreased (the $\Delta_{0.5}$ at $0.08 \mathrm{MeV}$ is higher than that at $0.1 \mathrm{MeV}$ ). Both ceramics contain $\mathrm{Bi}$ and $\mathrm{Pb}$, and it is 
known that at $0.1 \mathrm{MeV}$, the mass and linear attenuation coefficients of both elements are high (due to the K-absorption edge), and thus, the $\Delta_{0.5}$ is relatively small at this energy.

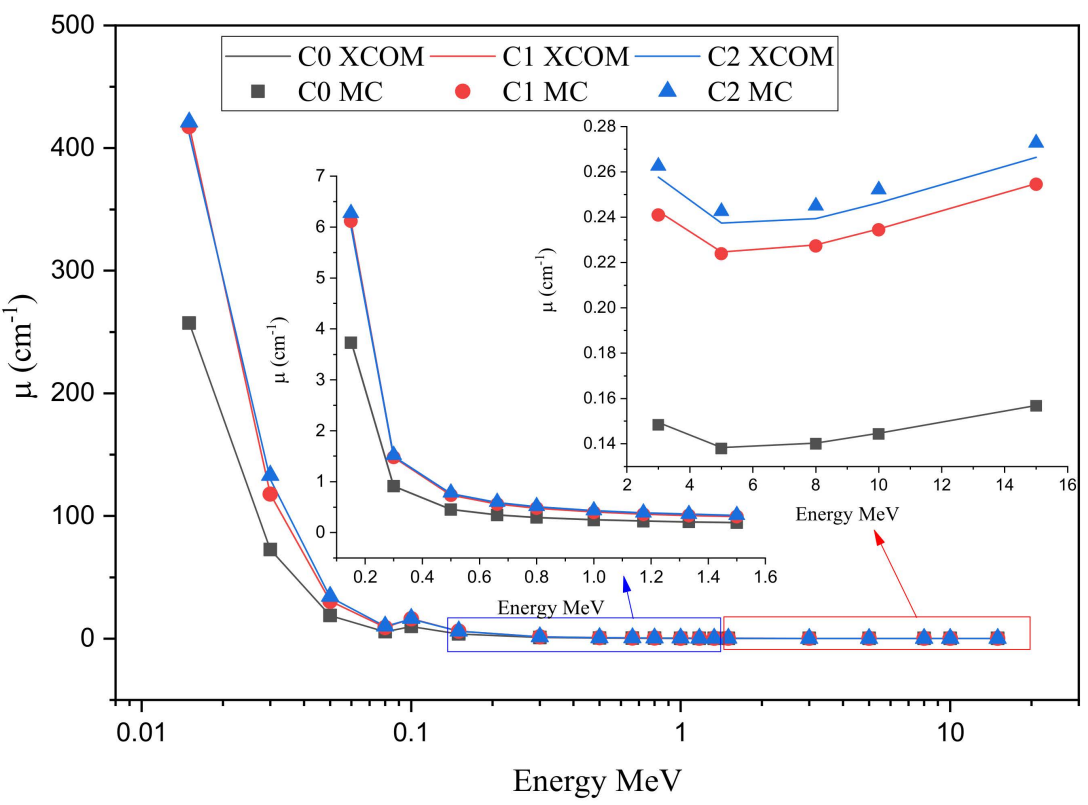

Figure 5. The linear attenuation coefficient of the fabricated ceramics samples.
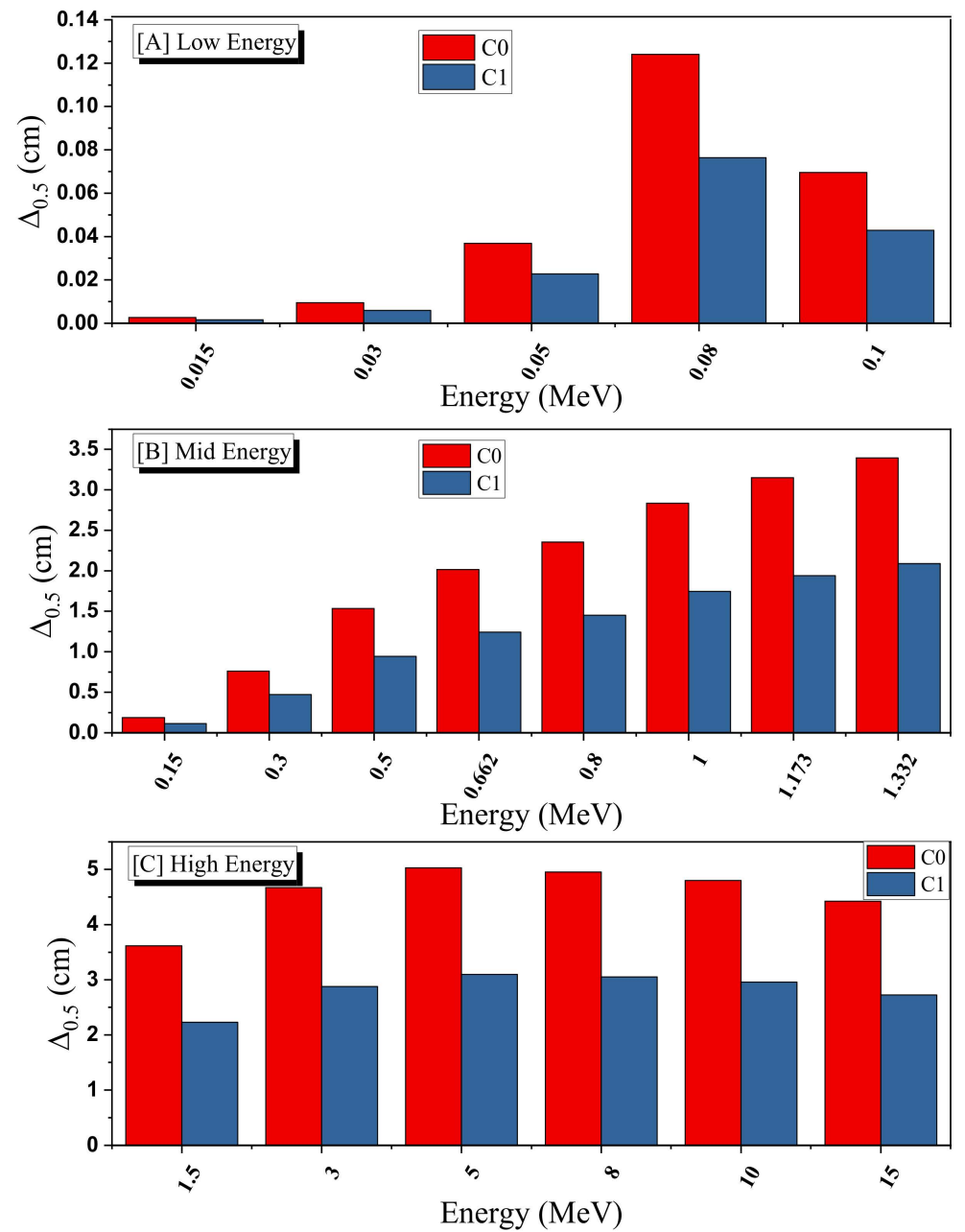

Figure 6. The effect of sintering on the half-value layer $\left(\Delta_{0.5}, \mathrm{~cm}\right)$ at $(\mathbf{A})$ low, $(\mathbf{B})$ mid and $(\mathbf{C})$ high energies. 

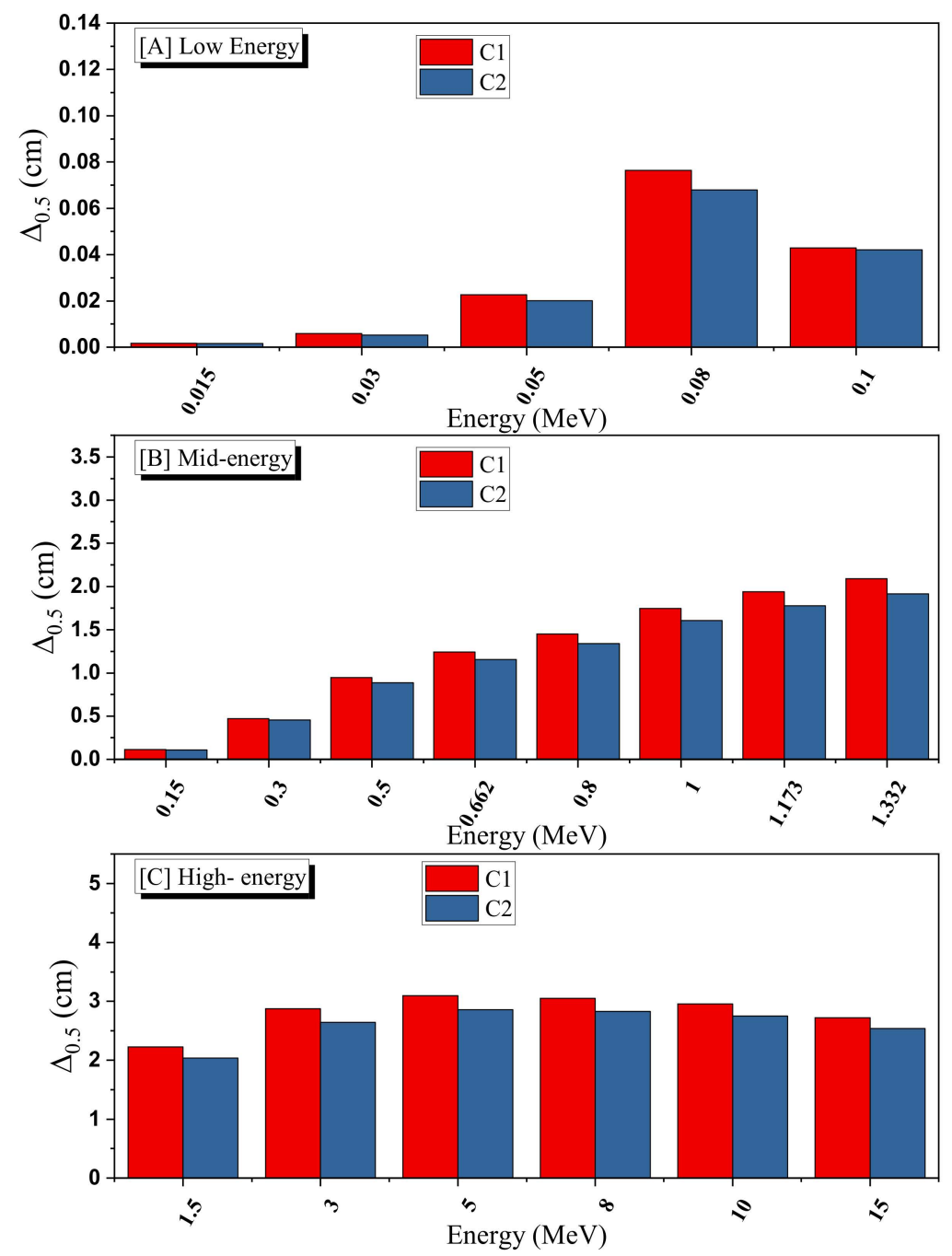

Figure 7. The effect of $\mathrm{AgNO}_{3}$ on the half-value layer $\left(\Delta_{0.5}, \mathrm{~cm}\right)$ at various gamma-ray energies.

From Figure 7 , it is obvious that the $\Delta_{0.5}$ for C2 is lower than that of C1. One must remember that the difference between both ceramics is the $\mathrm{AgNO}_{3}$. The reduction that occurred in the $\Delta_{0.5}$ for C2 should be mainly ascribed to enhancement in the density. As we note, the addition of $\mathrm{AgNO}_{3}$ in the $\mathrm{C} 2$ sample enhances the density, and this causes a reduction in the thickness of the sample that can attenuate the incoming radiation. However, the influence of the $\mathrm{AgNO}_{3}$ on the $\Delta_{0.5}$ is very small at low energy. At $0.015 \mathrm{MeV}$, the $\Delta_{0.5}$ for $\mathrm{C} 1$ and $\mathrm{C} 2$ are 0.00165 and $0.00164 \mathrm{~cm}$, respectively (the difference is negligible). The difference in the $\Delta_{0.5}$ between $C 1$ and $C 2$ is notable at higher energies. Thus, we can conclude that $\mathrm{C} 2$ exhibits better attenuation performance than $\mathrm{C} 0$ and $\mathrm{C} 1$, and it is promising for radiation shielding applications.

We investigated the influence of the thickness of the ceramics on the radiation shielding ability by evaluating the radiation protecting efficiency (RPE). This is obtained by applying the Lambert-Beer law and considering different thicknesses of each sample (i.e., 0.25, 0.5, 1, $1.5,2,2.5$, and $3 \mathrm{~cm}$ ). Figure 8 shows the variation in the RPE at the selected thicknesses for the three ceramics. The results are exhibited at one single energy (i.e., $1.332 \mathrm{MeV}$ ). With increasing thickness, the RPE ascends progressively from $4.97 \%$ for C0 with a thickness of $0.5 \mathrm{~cm}$ to $45.80 \%$ at $3 \mathrm{~cm}$, from $7.95 \%$ to $63.0 \%$ for C1, and from 8.65 to $66.24 \%$ for C2. If we examine the RPE at fixed thickness, we see the following order: $\mathrm{C} 2>\mathrm{C} 1>\mathrm{C} 0$. This reaffirms our observation in the previous figures that the sintering has a positive influence on the attenuation ability of the prepared ceramics and causes an enhancement in the radiation shielding performance (since $\mathrm{RPE}$ for $\mathrm{C} 1$ is higher than the RPE for $\mathrm{C} 0$ ). The 
results also reaffirm that the addition of $\mathrm{AgNO}_{3}$ causes an improvement in the radiation shielding performance for these ceramics.

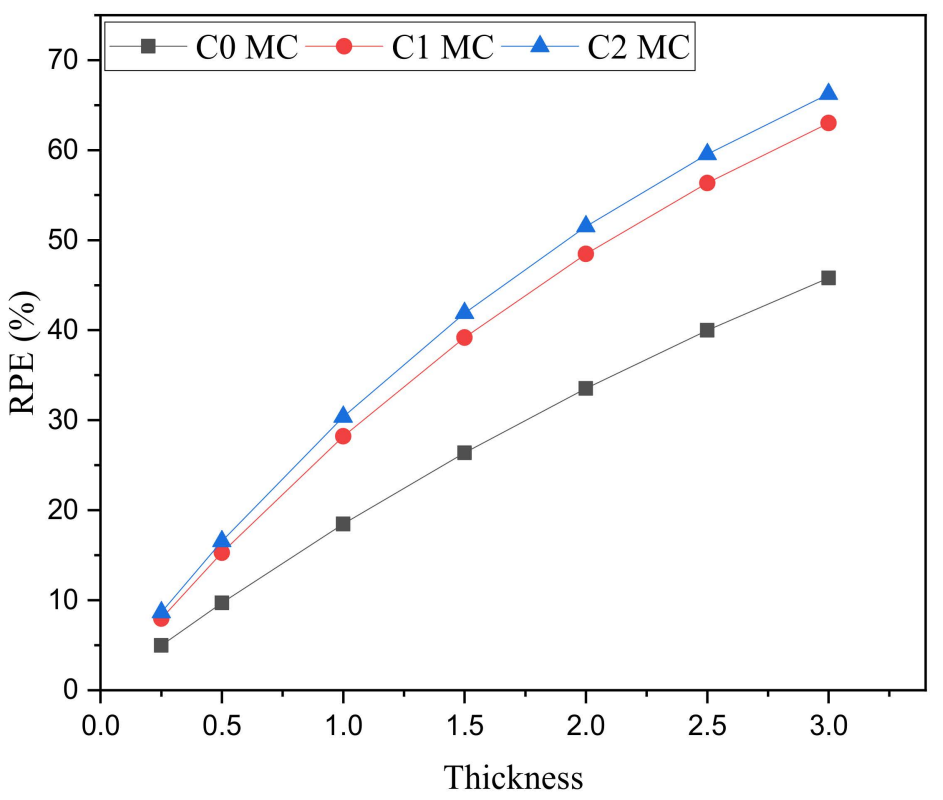

Figure 8. Variation in the radiation protecting efficiency of the fabricated ceramics versus the ceramics thickness at gamma ray energy of $1.332 \mathrm{MeV}$.

Based on the simulated $\mu$ values, the thickness of the fabricated ceramic equivalent to $1 \mathrm{~cm}$ of the pure lead element was calculated and plotted in Figure 9. At $0.015 \mathrm{MeV}$, the $\mathrm{D}_{\text {eq }}$ is 4.920, 3.031, and $3.005 \mathrm{~cm}$ for the ceramic samples C0, C1, and C2, respectively. The thicker $D_{\text {eq }}$ thickness at the mentioned energy is received for the $\mathrm{C} 0$ sample with a density of $3.85 \mathrm{~g} / \mathrm{cm}^{3}$ and without sintering. On the other hand, the thinner $\mathrm{D}_{\text {eq }}$ was achieved for both $\mathrm{C} 1$ and $\mathrm{C} 2$ with densities of $6.25 \mathrm{~cm}^{2} / \mathrm{g}$ and $6.85 \mathrm{~cm}^{2} / \mathrm{g}$, respectively. The sintering process utilized in the preparation of samples $C 1$ and $C 2$ helps to increase the density of the fabricated ceramics due to the application of heat and pressure. This increase in the density of the fabricated ceramics has a positive effect on the photon's passing resistance, so the $\mu$ values of the fabricated ceramics increase and $D_{\text {eq }}$ decreases as a result. After that, the $\mathrm{D}_{\text {eq }}$ for all ceramics samples were slight decreases in the energy range between 0.015 and $0.08 \mathrm{MeV}$. A significant increase in the $\mathrm{D}_{\mathrm{eq}}$ values was observed between 0.08 and $0.1 \mathrm{MeV}$, where the $D_{\text {eq }}$ values reach to maximum and have values of $6.322,3.893$, and $3.816 \mathrm{~cm}$ from samples C0, C1, and C2, respectively. This high decrease is due to the X-ray K-absorption edges of lead, which appear at $0.088 \mathrm{MeV}$. At the mentioned energy, the $\mu$ value for pure lead has a high unnormal jump. Thus, the $\mathrm{D}_{\text {eq }}$ also has an unnormal jump to higher levels. After that, in the Compton scattering region, the $D_{\text {eq }}$ regularly decreases with increasing the incident gamma photon energy. This behavior confirmed that the $\mu_{\mathrm{Pb}}$ for lead decreases regularly compared to the sample's $\mu$ values. Among the studied energy interval, the thinner $\mathrm{D}_{\text {eq }}$ obtained at $1.5 \mathrm{MeV}$ takes values of 3.090, 1.903, $1.742 \mathrm{~cm}$ for samples C0, C1, and $\mathrm{C} 2$, respectively. This thickness confirmed that, at the mentioned energy, the shielding efficiency of the C1 and C2 is higher than $50 \%$ as compared to the pure lead element, while the ceramic sample $\mathrm{C} 0$ has a shielding efficiency of about 33\% of the pure lead. This result clearly shows the effect of sintering on the shielding capacity of the fabricated ceramics. For $\mathrm{E}>1.5 \mathrm{MeV}$, the $\mathrm{D}_{\text {eq }}$ began to increase slightly with energy, which confirmed that at very high energy, the lead $\mu$ values increase slightly compared to the fabricated ceramic's $\mu$ values. 


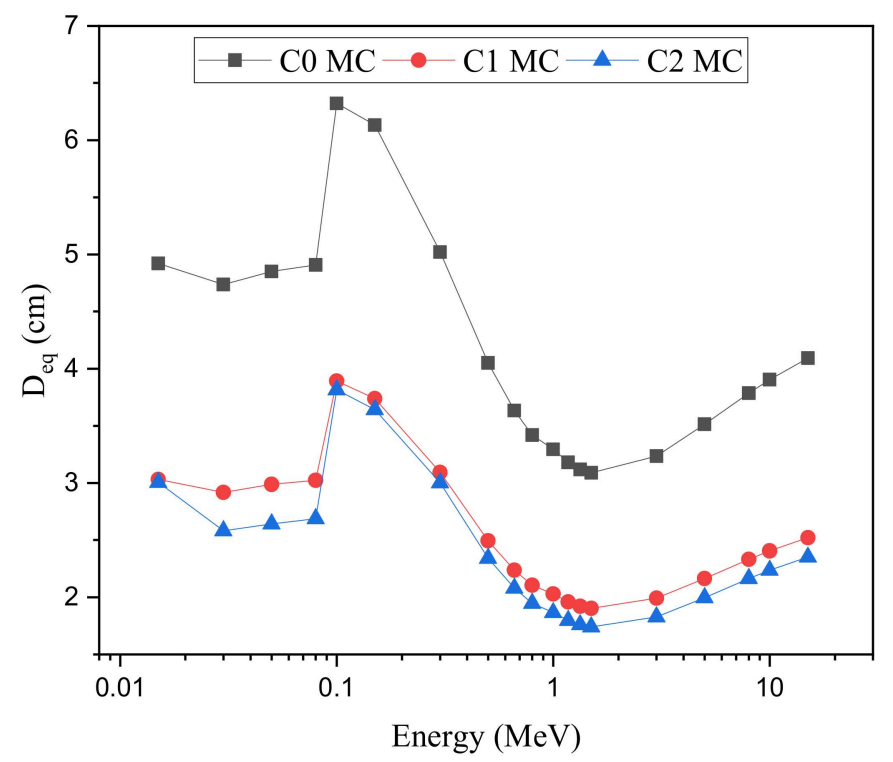

Figure 9. The fabricated ceramic's equivalent thickness $\left(D_{\text {eq }}\right)$ variation versus the gamma-ray energy.

\section{Conclusions}

We have conducted a comparative investigation of the formation phase and radiation protecting properties of three $(\mathrm{Bi}, \mathrm{Pb})-2223$ ceramics. $\mathrm{C} 0$ ceramic was obtained after calcination and one heat cycle. $\mathrm{C} 1$ and $\mathrm{C} 2$ ceramics were obtained after two cycles of sintering; $\mathrm{AgNO}_{3}$ was added at the beginning of the final sintering step to form a $\mathrm{C} 2$ ceramic. We showed growth of (Bi, Pb)-2223 phase during the second thermal cycle, while the Bi-2212 volume fraction decreased successively. Moreover, the addition of $\mathrm{AgNO}_{3}$ was significantly effective in further increasing the Bi-2223 phase from $53.3 \mathrm{vol} \%$ for $\mathrm{C} 1$ ceramic to $76.4 \mathrm{vol} \%$ for C2 ceramic and increasing the amount of grain interfacial conduction. The obtained results indicated that the sintering conditions and the addition of $\mathrm{AgNO}_{3}$ are among the most important determinants of the degradation rate of $(\mathrm{Bi}, \mathrm{Pb})-2212$ and the formation of the liquid phase and, thus, Bi-2223's transformation. The radiation shielding parameters of the different ceramics were calculated using Monte Carlo simulation. The difference between the MC and XCOM methods is extremely small, and less than $3 \%$ in most cases. We studied the influence of the sintering on the $\mu, \Delta_{0.5}$, and other shielding factors by comparing $\mathrm{C} 0$ with $\mathrm{C} 1$, while we studied the influence of $\mathrm{AgNO}_{3}$ on the shielding factors by comparing $\mathrm{C} 1$ with $\mathrm{C} 2$. The comparison between the $\mu$ for $\mathrm{C} 0$ and $\mathrm{C} 1$ proved that the sintering has a positive effect on the radiation shielding competence for the prepared ceramics. When we compared $\mu$ for $\mathrm{C} 1$ and $\mathrm{C} 2$, we found that the $\mathrm{AgNO}_{3}$ improves the radiation attenuation performance for the prepared ceramics. On the other hand, with increasing the thickness, the RPE ascends progressively from $4.97 \%$ for C 0 with a thickness of $0.5 \mathrm{~cm}$ to $45.80 \%$ at $3 \mathrm{~cm}$, from $7.95 \%$ to $63.0 \%$ for $\mathrm{C} 1$, and from 8.65 to $66.24 \%$ for C2. When we examined the RPE at fixed thickness, the following order was reported: $\mathrm{C} 2>\mathrm{C} 1>\mathrm{C} 2$, which reaffirms that the sintering and $\mathrm{AgNO}_{3}$ addition have a positive influence on the attenuation ability of the prepared ceramics and causes an enhancement in the radiation shielding performance. The results obtained are very motivating for the prospect of using the $\mathrm{Bi}(\mathrm{Pb})-\mathrm{Sr}-\mathrm{Ca}-\mathrm{Cu}-\mathrm{O}$ ceramic with the addition of $\mathrm{AgNO}_{3}$, using two thermal cycles, for radiation protection applications.

Author Contributions: Conceptualization, E.H.; methodology, E.H. and Y.S.; software, M.I.S. and K.A.M.; validation, M.I.S. and K.A.M.; formal analysis, E.H., Y.S., M.I.S. and K.A.M.; investigation, E.H., K.A.M., A.H.A., M.I.S. and Y.S.; data curation, E.H., K.A.M., M.I.S. and Y.S.; writing-original draft preparation, E.H., K.A.M., M.I.S. and Y.S.; writing-review and editing, E.H., K.A.M., A.H.A. M.I.S. and Y.S.; supervision, E.H. and M.I.S.; funding acquisition, A.H.A. All authors have read and agreed to the published version of the manuscript. 
Funding: The authors express their gratitude to Princess Nourah bint Abdulrahman University Researchers Supporting Project number (PNURSP2022R2), Princess Nourah bint Abdulrahman University, Riyadh, Saudi Arabia.

Institutional Review Board Statement: Not applicable.

Informed Consent Statement: Not applicable.

Data Availability Statement: All of the relevant data are within this paper.

Conflicts of Interest: The authors declare no conflict of interest.

\section{References}

1. Zimmerman, G.O. Superconductivity: The promise and reality. Int. J. Mod. Phys. B 2003, 17, 3698-3701. [CrossRef]

2. Bromberg, L.; Tekula, M.; El-Guebaly, L.A.; Miller, R.; ARIES Team. Options for the use of high temperature superconductor in tokamak fusion reactor designs. Fusion Eng. Des. 2001, 54, 167-180. [CrossRef]

3. Şahin, S.; Şahin, H.M.; Şahiner, H.; Tunç, G. Study on the fusion reactor performance with different materials and nuclear waste actinides. Int. J. Energy Res. 2021, 45, 11759-11774. [CrossRef]

4. Azzouz, F.B.; M'chirgui, A.; Yangui, B.; Boulesteix, C.; Ben Salem, M. Synthesis, microstructural evolution and the role of substantial addition of $\mathrm{PbO}$ during the final processing of $(\mathrm{Bi}, \mathrm{Pb})-2223$ superconductors. Phys. C Supercond. Appl. 2001, 356, 83-96. [CrossRef]

5. Annabi, M.; M'chirgui, A.; Ben Azzouz, F.; Zouaoui, M.; Ben Salem, M. Addition of nanometer $\mathrm{Al}_{2} \mathrm{O}_{3}$ during the final processing of (Bi, Pb)-2223 superconductors. Phys. C Supercond. Appl. 2004, 405, 25-33. [CrossRef]

6. Abou-Aly, A.I.; Abdel Gawad, M.M.H.; Awad, R.; G.-Eldeen, I. Improving the physical properties of (Bi, Pb)-2223 phase by SnO 2 nano-particles addition. J. Supercond. Nov. Magn. 2011, 24, 2077. [CrossRef]

7. Zhang, S.; Shao, B.; Zhang, W.; Ma, X.; Liu, J.; Liu, X.; Feng, J.; Wang, Q.; Li, C.; Zhang, P. Influences of Precursors Phase Com-position on the Phase Evolution Dynamics of Bi-2223 Superconducting Tapes. IEEE Trans. Appl. Supercond. 2021, 31, 1-6.

8. Sinuhaji, P.; Yuliana, Z. The Effect of Sintering Time on Superconductor Wire Bi-Pb-Sr-Ca-Cu-O with Dopant Te Sheeted Ag Using Powder In-Tube Method. J. Phys. Conf. Ser. 2018, 1120, 012027. [CrossRef]

9. Ben Salem, M.K.; Slimani, Y.; Hannachi, E.; Ben Azzouz, F.; Ben Salem, M. Bi-based superconductors prepared with addition of $\mathrm{CoFe}_{2} \mathrm{O}_{4}$ for the design of a magnetic probe. Cryogenics 2018, 89, 53-57. [CrossRef]

10. Ozturk, O.; Cetinkara, H.A.; Asikuzun, E.; Akdogan, M.; Yilmazlar, M.; Terzioglu, C. Investigation of mechanical and superconducting properties of iron diffusion-doped Bi-2223 superconductors. J. Mater. Sci. Mater. Electron. 2011, 22, 1501-1508. [CrossRef]

11. Loudhaief, N.; Labiadh, H.; Hannachi, E.; Zouaoui, M.; Ben Salem, M. Synthesis of CdS nanoparticles by hydrothermal method and their effects on the electrical properties of Bi-based superconductors. J. Supercond. Nov. Magn. 2018, 31, 2305-2312. [CrossRef]

12. Baalamurugan, J.; Ganesh Kumar, V.; Chandrasekaran, S.; Balasundar, S.; Venkatraman, B.; Padmapriya, R.; Raja, V.K.B. Recycling of steel slag aggregates for the development of high density concrete: Alternative \& environment-friendly radiation shielding composite. Compos. B Eng. 2021, 216, 108885.

13. Khalaf, M.A.; Cheah, C.B.; Ramli, M.; Ahmed, N.M.; Al-Shwaiter, A. Effect of nano zinc oxide and silica on mechanical, fluid transport and radiation attenuation properties of steel furnace slag heavyweight concrete. Constr. Build. Mater. 2021, 274, 121785. [CrossRef]

14. Tekin, H.O.; Sayyed, M.I.; Manici, T.; Altunsoy, E.E. Photon shielding characterizations of bismuth modified borate silicate tellurite glasses using MCNPX Monte Carlo code. Mater. Chem. Phys. 2018, 211, 9-16. [CrossRef]

15. Rammah, Y.S.; Mahmoud, K.A.; Mohammed, F.Q.; Sayyed, M.I.; Tashlykov, O.L.; El-Mallawany, R. Gamma ray exposure buildup factor and shielding features for some binary alloys using MCNP-5 simulation code. Nucl. Eng. Technol. 2021, 53, 2661-2668. [CrossRef]

16. Rammah, Y.S.; Abouhaswa, A.S.; Sayyed, M.I.; Tekin, H.O.; El-Mallawany, R. Structural, UV and shielding properties of ZBPC glasses. J. Non-Cryst. Solids 2019, 509, 99-105. [CrossRef]

17. Almuqrin, A.H.; Kumar, A.; Jecong, J.F.M.; Al-Harbi, N.; Hannachi, E.; Sayyed, M.I. Li ${ }_{2} \mathrm{O}-\mathrm{K}_{2} \mathrm{O}_{-} \mathrm{B}_{2} \mathrm{O}_{3}-\mathrm{PbO}$ glass system: Optical and gamma-ray shielding investigations. Optik 2021, 247, 167792. [CrossRef]

18. Singh, V.P.; Medhat, M.E.; Badiger, N.M.; Saliqur Rahman, A.Z.M. Radiation shielding effectiveness of newly developed superconductors. Radiat. Phys. Chem. 2015, 106, 175-183. [CrossRef]

19. Hannachi, E.; Slimani, Y.; Ben Salem, M.K.; Hamrita, A.; Al-Otaibi, A.L.; Almessiere, M.A.; Ben Salem, M.; Ben Azzouz, F. Fluctuation induced conductivity studies in $\mathrm{YBa}_{2} \mathrm{Cu}_{3} \mathrm{O}_{\mathrm{y}}$ compound embedded by superconducting nano-particles Y-deficient $\mathrm{YBa}_{2} \mathrm{Cu}_{3} \mathrm{O}_{\mathrm{y}}$ : Effect of silver inclusion. Indian J. Phys. 2016, 90, 1009-1018. [CrossRef]

20. Singh, J.P.; Leu, H.J.; Poeppel, R.B.; Van Voorhees, E.; Goudey, G.T.; Winsley, K.; Shi, D. Effect of silver and silver oxide additions on the mechanical and superconducting properties of $\mathrm{YBa}_{2} \mathrm{Cu}_{3} \mathrm{O}_{7-\delta}$ superconductors. J. Appl. Phys. 1989, 66, 3154-3159. [CrossRef]

21. Anand, S.; Srivastava, O.N. Effect of $\mathrm{AgNO}_{3}$ additive/doping on microstructure and superconductivity of the $\mathrm{Pb}$ doped $\mathrm{Hg}$ : 1223 thin film prepared through spray pyrolysis. J. Phys. Chem. Solids 2002, 63, 1647-1653. [CrossRef] 
22. Abdeen, W.; Mohammed, N.H.; Awad, R.; Mahmoud, S.A.; Hasebbo, M. Influence of Nano-Ag Addition on the Mechanical Properties of $\left(\mathrm{Cu}_{0.5} \mathrm{Tl}_{0.5}\right)_{-1223}$ Superconducting Phase. J. Supercond. Nov. Magn. 2013, 26, 3235-3245. [CrossRef]

23. Mawassi, R.; Marhaba, S.; Roumié, M.; Awad, R.; Korek, M.; Hassan, I. Improvement of superconducting parameters of $\mathrm{Bi}_{1.8} \mathrm{~Pb}_{0.4} \mathrm{Sr}_{2} \mathrm{Ca}_{2} \mathrm{Cu}_{3} \mathrm{O}_{10+\delta}$ added with nano-Ag. J. Supercond. Nov. Magn. 2014, 27, 1131-1142. [CrossRef]

24. Sýkorová, D.; Jakeš, V.; Smrčková, O. Bi-based superconductors with nanosized silver dopant. Phys. Status Solidi C 2006, 3 , 3027-3030. [CrossRef]

25. Romano, P.K.; Forget, B. The Open MC Monte Carlo particle transport code. Ann. Nucl. Energy 2013, 51, 274-281. [CrossRef]

26. Sayyed, M.I.; Hannachi, E.; Mahmoud, K.A.; Slimani, Y. Synthesis of different (RE)BaCuO ceramics, study their structural properties, and tracking their radiation protection efficiency using Monte Carlo simulation. Mater. Chem. Phys. 2022, $276,125412$. [CrossRef]

27. El-Soad, A.M.A.; Sayyed, M.I.; Mahmoud, K.A.; Şakar, E.; Kovaleva, E.G. Simulation studies for gamma ray shielding properties of Halloysite nanotubes using MCNP-5 code. Appl. Radiat. Isot. 2019, 154, 108882. [CrossRef]

28. Pakdil, M.; Bekiroglu, E.; Oz, M.; Saritekin, N.K.; Yildirim, G. Role of preparation conditions of Bi-2223 ceramic materials and optimization of Bi-2223 phase in bulk materials with experimental and statistical approaches. J. Alloys Compd. 2016, 673, 205-214. [CrossRef]

29. Hannachi, E.; Almessiere, M.A.; Slimani, Y.; Baykal, A.; Azzouz, F.B. AC susceptibility investigation of YBCO superconductor added by carbon nanotubes. J. Alloys Compd. 2020, 812, 152150. [CrossRef]

30. Kaky, K.M.; Sayyed, M.I.; Ati, A.A.; Mhareb, M.H.; Mahmoud, K.A.; Baki, S.O.; Mahdi, M.A. Germanate oxide impacts on the optical and gamma radiation shielding properties of $\mathrm{TeO}_{2}-\mathrm{ZnO}-\mathrm{Li}_{2} \mathrm{O}$ glass system. J. Non-Cryst. Solids 2020, 546, 120272. [CrossRef] 